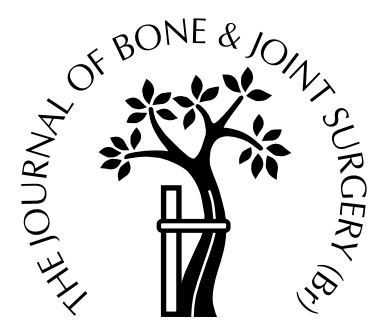

\title{
The routine of surgical management reduces failure after unicompartmental knee arthroplasty
}

\author{
O. Robertsson, K. Knutson, S. Lewold, L. Lidgren \\ From the University Hospital, Lund, Sweden
}

\begin{abstract}
A total of 10474 unicompartmental knee arthroplasties was performed for medial osteoarthritis in Sweden between 1986 and 1995. We sought to establish whether the number of operations performed in an orthopaedic unit affected the incidence of revision. Three different implants were analysed: one with a high revision rate, known to have unfavourable mechanical and design properties; a prosthesis which is technically demanding with a known increased rate of revision; and the most commonly used unicompartmental device.

Most of the units performed relatively few unicompartmental knee arthroplasties per year and there was an association between the mean number carried out and the risk of later revision. The effect of the mean number of operations per year on the risk of revision varied. The technically demanding implant was most affected, that most commonly used less so, and the outcome of the unfavourable design was not influenced by the number of operations performed.

For unicompartmental arthroplasty, the long-term results are related to the number performed by the unit, probably expressing the standards of management in selecting the patients and performing the operation.
\end{abstract}

J Bone Joint Surg [Br] 2001;83-B:45-9.

Received 23 December 1999; Accepted after revision 21 June 2000

The outcome after knee arthroplasty is often presented as the rate of failure as assessed by the requirement for revision. Factors which influence the incidence of revision may be related to the patient, to the implant and to the surgical technique. The rate of revision has been shown to be related to the type of joint disease, the age of the patient

O. Robertsson, MD, PhD, Orthopaedic Surgeon

K. Knutson, MD, PhD, Assistant Professor

S. Lewold, MD, PhD, Orthopaedic Surgeon

L. Lidgren, MD, PhD, Professor

Department of Orthopaedics, University Hospital, 22185 Lund, Sweden.

Correspondence should be sent to Dr O. Robertsson.

(C)2001 British Editorial Society of Bone and Joint Surgery 0301-620X/01/110871\$2.00 at surgery (and thus their level of activity), the type of implant used and the year of operation. ${ }^{1}$

While the choice of prosthesis and the technique used at operation are influenced by the implants and information available at the time of operation, the skill of the surgeon, his judgement as to the indications for surgery and the operative routine may be assumed to be influenced by the number of procedures which he performs. It has been claimed that unicompartmental arthroplasty (UKA) is more surgically demanding than total knee arthroplasty (TKA) ${ }^{2}$ and hence the outcome is therefore more likely to be related to surgical skill and operative routine.

The Swedish Knee Arthroplasty Register (SKAR) records the hospital where the operation is performed, but not the name of the operating surgeon. We have assessed the mean number of UKAs performed per year in orthopaedic units and investigated its influence on the incidence of revision after primary procedures carried out for medial osteoarthritis. The results after the insertion of three different implants were analysed.

\section{Patients and Methods}

The SKAR records primary and revision arthroplasties performed in Sweden since 1975, with revision defined as adding to, removing or exchanging of prosthetic components. ${ }^{1}$ During the ten-year period from 1986 to 1995 , 12524 UKAs were reported to the register, of which 10474 were primary operations for medial osteoarthritis. After update of the register $94 \%$ of revisions could be accounted for; $1 \%$ of patients could not be traced. ${ }^{3}$

The procedures were performed at 78 units with the total number of operations at each site varying from 2 to 600 . The mean number of UKA operations carried out per year at the different departments during the period was calculated. This figure was low for most (Fig. 1); 25\% of units performed less than 7.8 operations per year, $50 \%$ less than 14 , and $75 \%$ less than 23 .

We designated the $75 \%$ in which less than 23 UKA operations per year were performed as group A (46\% of operations) and the $25 \%$ carrying out 23 or more procedures per year as group B ( $54 \%$ of operations).

Three prostheses which were widely used were analysed. Model I (PCA; Duracon Total Knee System; Howmedica 


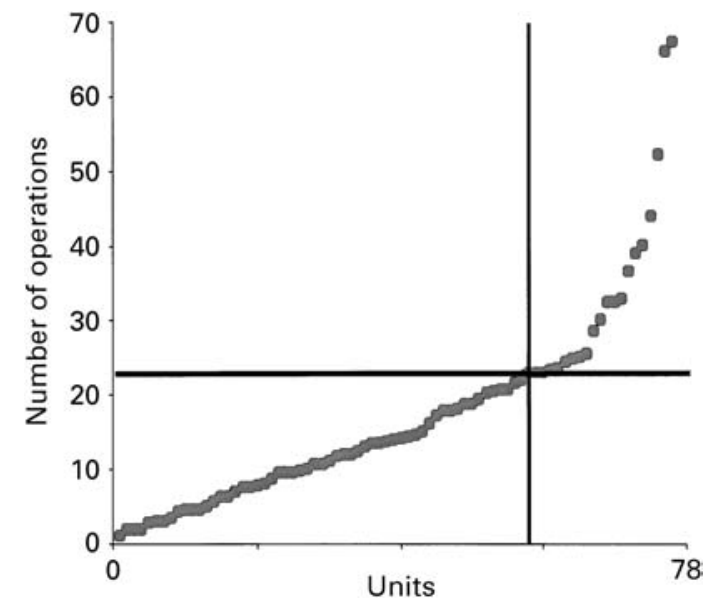

Fig. 1

Graph showing the mean number of UKA operations per year performed at each unit in Sweden between 1986 and 1995. Only 20 of the 78 units performed 23 or more operations per year.

Osteonics, Rutherford, USA; 874 knees) is associated with an increased rate of revision because of inferior mechanical and design properties. ${ }^{4,5}$ Model II (Oxford meniscal knee; Biomet Ltd, Bridgend, UK; 905 knees), is a technically demanding implant which requires exact balancing and intact cruciate ligaments because of the mobile meniscus. In spite of favourable reports from the originating centre in the UK, ${ }^{6,7}$ it has been associated with an increased rate of revision in Sweden. ${ }^{8}$ Model III (Endo-Link and St Georg; Waldemar Link GmbH, Hamburg, Germany; 4307 knees) is commonly used in Sweden. ${ }^{5,9}$ We investigated the effect of the mean number of operations per year on the rate of revision.

Statistical analysis. We used survivorship statistics. Although such methods allow for different lengths of follow-up, they are sensitive to the choice of endpoint and patients lost to follow-up are considered to have the same rate of failure as those who complete the trial. ${ }^{10}$

The risk ratios were calculated using Cox's regression analysis. The risk ratio of a variable is expressed after adjusting for the effect of other explanatory variables in the model. For categorical variables in the model, one category is defined as a reference (coded 0 ) having the relative risk of 1.0 with which the other categories are then compared. For numerical variables, the risk ratio relates to the change in risk if the variable increases by one unit (e.g. an increase of one in the mean number of operations per year or an increase in age of the patient of one year or performance of the operation one year later).

When the risk ratios of models I and II were compared with that of model III, these implants $(n=6086)$ were used in the regression model as category variables (model III coded as 0 , reference). The year of the operation and the age of the patient were included as numerical variables, with the year of the primary operation, 1986 to 1995, as an integer and the age of the patient at the time of the primary operation as a numerical value, while the gender of the patients was a categorical variable (males coded as 0 , reference). The operative volume (the mean number of operations per year or the classification A or B) was not included in this analysis.

When performing Cox's regression analyses and investigating the influence of the operative volume on the risk ratio, two methods were used. In the first, units were classed as categorical variables and divided into groups A and $\mathrm{B}$ depending on their mean number of operations per year $(A<23, B \geq 23)$ with group $B$ as a reference. In the second method the mean number of operations per year was used in the regression model as a numerical variable. Otherwise, the regression models were the same, including the age, gender and year of operation.

For graphical representation, the cumulative revision rate was calculated by the life-table method using one-month intervals and plotted with confidence intervals (CI) calculated using the Wilson quadratic equation with Greenwood and Peto effective sample-size estimates. ${ }^{11}$ Curves were cut off when 40 knees remained at risk. We used SPSS software (SPSS Inc, Chicago, Illinois) for statistical calculations.

\section{Results}

Models I and II were compared with model III with respect to the incidence of revision after adjustment for age, gender and the year of operation, but not the operative volume of the units (Table I).

Table I. Cox regression tables for UKAs performed in Sweden using models I to III for medial osteoarthritis between 1986 and 1995. Model III $(n=4307)$ is the reference to which model I $(n=874)$ and model II $(n=905)$ are compared. The volume of operations $($ mean number of operations or group A/B) is not taken into consideration

\begin{tabular}{|c|c|c|c|c|c|c|c|c|}
\hline Variable & $\mathbf{B}^{*}$ & SEM & Wald $\dagger$ & df $\div$ & p value & $\mathbf{R}$ & Risk ratio & $95 \%$ CI for risk ratio \\
\hline Gender (males reference) & -0.1183 & 0.0965 & 1.5015 & 1 & 0.2204 & 0.0000 & 0.8885 & 0.7353 to 1.0735 \\
\hline Age & -0.0331 & 0.0065 & 26.2322 & 1 & 0.0000 & -0.0565 & 0.9675 & 0.9553 to 0.9798 \\
\hline Year of operation & -0.0144 & 0.0253 & 0.3229 & 1 & 0.5699 & 0.0000 & 0.9857 & 0.9380 to 1.0359 \\
\hline Reference (Model III) & & & 116.0524 & 2 & 0.0000 & 0.1215 & & \\
\hline Model I & 1.1763 & 0.1099 & 114.4862 & 1 & 0.0000 & 0.1217 & 3.2425 & 2.6140 to 4.0222 \\
\hline Model II & 0.6542 & 0.1266 & 26.7123 & 1 & 0.0000 & 0.0571 & 1.9236 & 1.5010 to 2.4653 \\
\hline
\end{tabular}

* estimated regression coefficient

$\dagger$ test statistic

$\ddagger$ degree of freedom 
Table II. Cox regression tables for all 10474 medial UKAs performed in Sweden for osteoarthritis between 1986 and 1995 . The upper part compares group A ( $<23$ mean operations per year) with that of group B ( $\geq 23$ mean operations per year). The lower part uses the mean number of operations per year as a continuous explanatory variable. For explanation of symbols see Table I

\begin{tabular}{|c|c|c|c|c|c|c|c|c|}
\hline Variable & $\mathbf{B}^{*}$ & SEM & Wald & df & p value & $\mathbf{R}$ & Risk ratio & $95 \%$ CI for risk ratio \\
\hline Gender (males reference) & -0.0362 & 0.0770 & 0.2203 & 1 & 0.6388 & 0.0000 & 0.9645 & 0.8293 to 1.1217 \\
\hline Age & -0.0365 & 0.0051 & 52.1094 & 1 & 0.0000 & 0.0633 & 0.9641 & 0.9546 to 0.9737 \\
\hline Year of operation & -0.0239 & 0.0179 & 1.7727 & 1 & 0.1831 & 0.0000 & 0.9764 & 0.9427 to 1.0113 \\
\hline Group (B reference) & 0.4889 & 0.0755 & 41.9483 & 1 & 0.0000 & 0.0565 & 1.6305 & 1.4063 to 1.8905 \\
\hline Gender (males reference) & -0.0369 & 0.0770 & 0.2295 & 1 & 0.6319 & 0.0000 & 0.9638 & 0.8287 to 1.1208 \\
\hline Age & -0.0371 & 0.0051 & 53.8190 & 1 & 0.0000 & -0.0644 & 0.9635 & 0.9540 to 0.9732 \\
\hline Year of operation & -0.0270 & 0.0180 & 2.2545 & 1 & 0.1332 & -0.0045 & 0.9734 & 0.9397 to 1.0083 \\
\hline Mean op/year & -0.0129 & 0.0023 & 29.9433 & 1 & 0.0000 & -0.0473 & 0.9872 & 0.9827 to 0.9918 \\
\hline
\end{tabular}

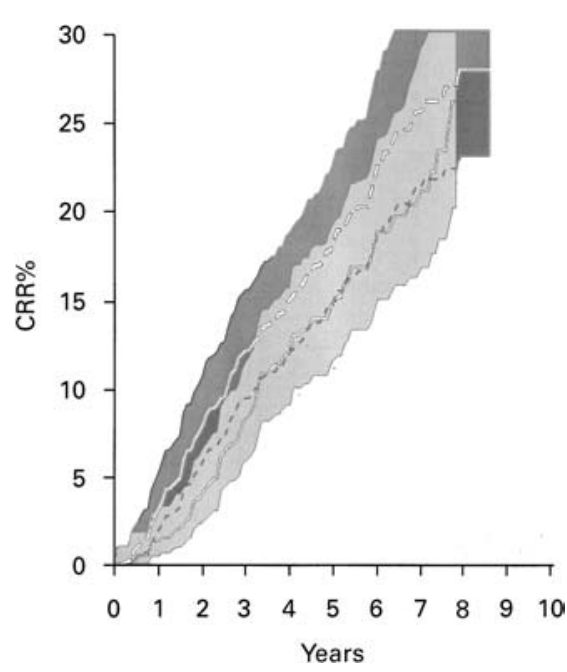

Fig. 2a

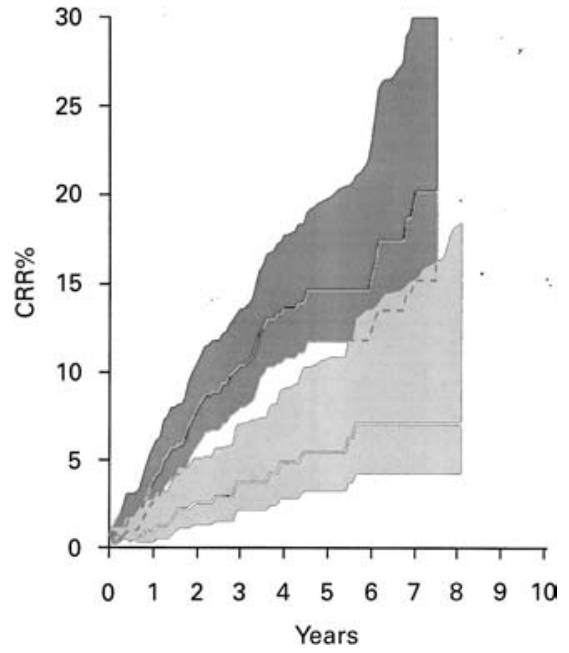

Fig. 2b

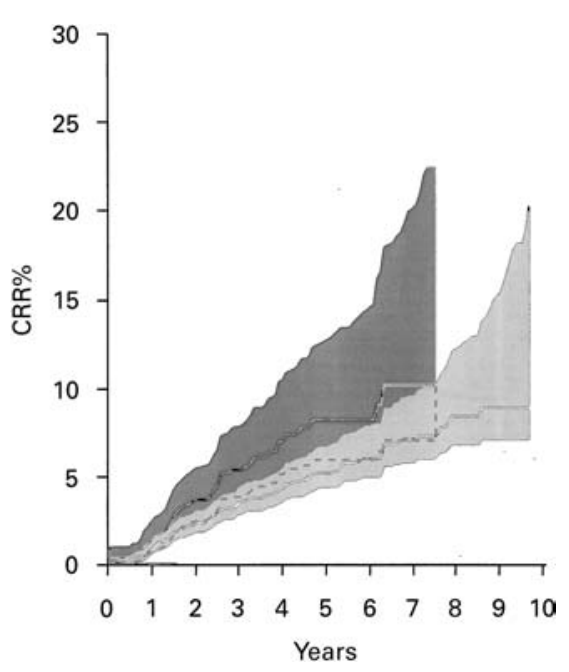

Fig. 2c

Graphs showing percentage cumulative revision rate (CRR \%) (see text for details) for a) 874 knees operated on using an implant with known mechanical and design problems (model I); b) 905 knees operated on using a technically demanding implant (model II); and c) 4307 knees operated on using a commonly used implant (model III). Lines represent the cumulative revision rate and shaded areas the $95 \%$ confidence interval. The dark areas are surgical units performing a mean of less than 23 operations/year: a) $(n=476)$; b) $(n=566)$; c) $(n=1027)$. The light area represents surgical units performing a mean of 23 or more operations/year: a) $(n=398)$; b) $(n=339)$; c) $(n=3280)$.

Model I was found to have a risk of 3.24 times (95\% CI 2.61 to 4.02 ) that for model III of requiring revision, while model II had a risk of 1.92 times (95\% CI 1.50 to 2.47 ) that for model III.

To evaluate the effect of operative volume on the risk of revision, we first compared the risk of revision in units in group A (performing less) with that in units in group B (performing more), and secondly we directly related the mean number of operations per year to the incidence of revision.

All medial UKAs. When analysed together (Table II) group $\mathrm{A}(<23)$ had a risk of revision of 1.63 times $(95 \% \mathrm{CI}$ 1.41 to 1.89$)$ that of group B (>23). Cox's regression analysis using the mean number of UKAs per year instead of the two groups also showed a significantly lower risk of revision with an increasing number of operations (risk ratio $=0.99,95 \%$ CI 0.98 to 0.99 ).

Model I (Fig. 2a, Table III). We found no significant difference in the risk of revision between groups $\mathrm{A}$ and $\mathrm{B}$ (95\% CI 0.81 to 1.48 ). When the mean number of UKAs per year was used instead of the groups, the regression analysis also failed to show a reduced incidence with an increasing number of operations (95\% CI 0.99 to 1.02).

Model II (Fig. 2b, Table IV). The risk of revision in group A was found to be 3.07 times that of group B (95\% CI 1.78 to 5.29). When the mean number per year was analysed instead of groups, the Cox regression also showed a reduced incidence with increasing number of operations (risk ratio $=0.96,95 \%$ CI 0.93 to 0.99 ).

Model III (Fig. 2c, Table V). Group A had a higher risk of revision of 1.53 times ( $95 \%$ CI 1.10 to 2.12) that of group B. In spite of this difference between the groups, using the mean number of UKAs per year in the Cox regression failed to detect a significant reduction in the rate of revision with an increase in the number of operations (risk ratio $=0.99,95 \% \mathrm{CI} 0.98$ to 1.00$)$. This was probably because although the results in units performing 23 or more operations per year were better than those of units performing fewer procedures, there was a lack of direct association between the risk of revision and the number of operations carried out, i.e., the results did not improve further when doing still more than 23 operations. 
Table III. Cox regression tables for 874 UKAs performed in Sweden using model I for medial osteoarthritis between 1986 and 1995. The upper part compares group A ( $<23$ mean operations per year) with that of group B ( $\geq 23$ mean operations per year). The lower part uses the mean number of operations/year as a continuous explanatory variable. For explanation of symbols see Table I

\begin{tabular}{|c|c|c|c|c|c|c|c|c|}
\hline Variable & B* & SEM & Wald & df & p value & $\mathbf{R}$ & Risk ratio & $95 \%$ CI for risk ratio \\
\hline Gender (males reference) & -0.3805 & 0.1550 & 6.0272 & 1 & 0.0141 & -0.0418 & 0.6835 & 0.5044 to 0.9261 \\
\hline Age & -0.0554 & 0.0101 & 30.2803 & 1 & 0.0000 & -0.1107 & 0.9461 & 0.9276 to 0.9649 \\
\hline Year of operation & -0.1176 & 0.0542 & 4.7121 & 1 & 0.0300 & -0.0343 & 0.8891 & 0.7995 to 0.9886 \\
\hline Group (B reference) & 0.0899 & 0.1526 & 0.3472 & 1 & 0.5557 & 0.0000 & 1.0941 & 0.8113 to 1.4753 \\
\hline Gender (males reference) & -0.3843 & 0.1550 & 6.1484 & 1 & 0.0132 & -0.0424 & 0.6810 & 0.5026 to 0.9226 \\
\hline Age & -0.0570 & 0.0101 & 32.0778 & 1 & 0.0000 & -0.1142 & 0.9446 & 0.9262 to 0.9634 \\
\hline Year of operation & -0.1227 & 0.0547 & 5.0295 & 1 & 0.0249 & -0.0362 & 0.8845 & 0.7945 to 0.9846 \\
\hline Mean op/year & 0.0068 & 0.0077 & 0.7733 & 1 & 0.3792 & 0.0000 & 1.0068 & 0.9917 to 1.0221 \\
\hline
\end{tabular}

Table IV. Cox regression tables for 905 UKAs performed in Sweden using model II for medial osteoarthritis between 1986 and 1995. The upper part compares groups A ( $<23$ mean operations per year) with that of group B ( $\geq 23$ mean operations per year). The lower part uses the mean number of operations/year as a continuous explanatory variable. For explanation of symbols see Table I

\begin{tabular}{|c|c|c|c|c|c|c|c|c|}
\hline Variable & B* & SEM & Wald & df & p value & $\mathbf{R}$ & Risk ratio & $95 \%$ CI for risk ratio \\
\hline Gender (males reference) & 0.0690 & 0.2145 & 0.1035 & 1 & 0.7477 & 0.0000 & 1.0714 & 0.7037 to 1.6313 \\
\hline Age & -0.0116 & 0.0146 & 0.6340 & 1 & 0.4259 & 0.0000 & 0.9884 & 0.9696 to 1.0171 \\
\hline Year of operation & -0.0572 & 0.0582 & 0.9664 & 1 & 0.3256 & 0.0000 & 0.9444 & 0.8427 to 1.0585 \\
\hline Group (B reference) & 1.1219 & 0.2776 & 16.3325 & 1 & 0.0001 & 0.1092 & 3.0706 & 1.7821 to 5.2907 \\
\hline Gender (males reference) & 0.0988 & 0.2145 & 0.2123 & 1 & 0.6449 & 0 & 1.1039 & 0.725 to 1.6808 \\
\hline Age & -0.0095 & 0.0147 & 0.42 & 1 & 0.5169 & 0 & 0.9905 & 0.9623 to 1.0195 \\
\hline Year of operation & -0.0582 & 0.0568 & 1.0494 & 1 & 0.3056 & 0 & 0.9435 & 0.8441 to 1.0546 \\
\hline Mean op/year & -0.0434 & 0.0146 & 8.8527 & 1 & 0.0029 & -0.0755 & 0.9576 & 0.9306 to 0.9853 \\
\hline
\end{tabular}

Table V. Cox regression tables for 4307 UKAs performed in Sweden using model III for medial osteoarthritis during 1986 to 1995 . The upper part compares group A ( $<23$ mean operations/year) with that of group B ( $\geq 23$ mean operations/year). The lower part uses the mean number of operations/year as a continuous explanatory variable. For explanation of symbols see text

\begin{tabular}{|c|c|c|c|c|c|c|c|c|}
\hline Variable & B* & SEM & Wald & df & p value & $\mathbf{R}$ & Risk ratio & 95\% CI for risk ratio \\
\hline Gender (males reference) & 0.0075 & 0.1491 & 0.0026 & 1 & 0.9597 & 0.0000 & 1.0076 & 0.7522 to 1.3496 \\
\hline Age & -0.0190 & 0.0101 & 3.5555 & 1 & 0.0593 & -0.0228 & 0.9812 & 0.9620 to 1.0007 \\
\hline Year of operation & -0.0020 & 0.0357 & 0.0033 & 1 & 0.9543 & 0.0000 & 0.9980 & 0.9305 to 1.0702 \\
\hline Group (B reference) & 0.4252 & 0.1669 & 6.4918 & 1 & 0.0108 & 0.0387 & 1.5299 & 1.1031 to 2.1219 \\
\hline Gender (males reference) & -0.0078 & 0.1491 & 0.0027 & 1 & 0.9585 & 0.0000 & 0.9923 & 0.7409 to 1.3290 \\
\hline Age & -0.019 & 0.0101 & 3.5825 & 1 & 0.0584 & -0.023 & 0.9811 & 0.962 to 1.0007 \\
\hline Year of operation & -0.0049 & 0.0365 & 0.0177 & 1 & 0.8941 & 0 & 0.9952 & 0.9265 to 1.0689 \\
\hline Mean op/year & -0.0076 & 0.0045 & 2.9167 & 1 & 0.0877 & -0.0175 & 0.9924 & 0.9837 to 1.0011 \\
\hline
\end{tabular}

\section{Discussion}

A disadvantage of this study is that the mean number of operations performed per year is linked to an orthopaedic unit but not to the surgeon performing the operation. Thus, in one unit doing relatively few operations, all cases may be handled by one surgeon, while in another with more procedures, they would be performed by many surgeons. Therefore, in group A, in which fewer operations were performed, only one operation was done every second week, which is a low volume even for a single surgeon, while in group B, in which there were more operations, individual surgeons may have carried out both fewer and more procedures. This would reduce the effect of volume differences between the groups.
Were the differences in the incidence of revision between groups A and B (for models II and II) caused by the operative volume or other factor(s) linked to the different hospitals? There are several factors which may be involved, such as differences in the patients admitted to the units, the shelf-life of the implant (lower turnover/older polyethylene), the availability of sizes (few operations so few implants available), and surgical skill. We believe that a probable reason is a difference in the surgical management, expressing the combined skills of deciding the indications for surgery, of carrying out the operation and of providing a suitable postoperative regime, which may be better at a centre where a procedure is performed often, even by many surgeons each doing a few, than in one with a single surgeon undertaking few operations. 
Apart from the comparison of units in groups A and B we also used the mean number of operations per year as an explanatory variable in four sets of the regression analyses (all implants together and models I, II and III). For model III there was some discrepancy in the results, with the first analysis showing a difference in the incidence between groups A and B, while the second did not reveal the mean number per year to be a significant explanatory variable. There can be many reasons for this discrepancy: model III was the most common model and was used 2.4 times more often than models I and II combined. It was also introduced earlier. Thus it is possible that there is a breaking point in the mean number of operations per year, after which results do not improve and that with the introduction of newer models, the previous established implant became the choice for more inexperienced surgeons, or that the choice of patient changed. For model III we can only establish that the units in group A performing less than 23 operations per year had a higher incidence of revision that those in group $\mathrm{B}$, but overall the mean number of procedures per year was not significantly associated with an increased incidence of revision.

The type of joint disease, the age of the patients at operation and their level of activity may affect the rate of revision. The indications for operation are a significant factor in the outcome. A low volume of surgery for arthroplasties has previously been associated with an increased length of stay in hospital and cost, ${ }^{12,13}$ and of increased mortality. ${ }^{14}$ Espehaug et $\mathrm{al}^{15}$ found that the volume of operations affected the incidence of revision for uncemented hip arthroplasties but not for cemented. The reason may be that uncemented arthroplasty requires greater surgical skill. Our findings, with a large variation in the incidence of revision depending on the volume of operations for one of the implants (model II), may explain why the rate of revision in Sweden in many units is higher ${ }^{8}$ than that reported from the originating centres in the UK. ${ }^{6,7}$

On the basis of our study, we conclude that there is an association between the number of UKAs performed in a unit and the incidence of subsequent revisions, and while implants are differently sensitive to the routine of surgical management, such routine does not help implants with inferior mechanical properties.
This study was financially supported by MFR(09509), Stiftelsen för bistånd åt vanföra i Skåne, Socialstyrelsen/Landstingförbundet and Med Faculty.

No benefits in any form have been received or will be received from a commercial party relateddirectly or indirectly to the subject of this article.

\section{References}

1. Knutson K, Lewold S, Robertsson O, Lidgren L. The Swedish knee arthroplasty register: a nationwide study of 30003 knees 1976-1992. Acta Orthop Scand 1994;65:375-86.

2. Sculco TP. The case for total knee replacement in unicompartmental knee arthritis. Orthopedics 1994;9:857-8.

3. Robertsson O, Dunbar M, Knutson K, Lewold S, Lidgren L. Validation of the Swedish knee arthroplasty register: a postal survey regarding 30376 knees operated on between 1975 and 1995. Acta Orthop Scand 1999;70:467-72.

4. Bergenudd H. Porous-coated anatomic unicompartmental knee arthroplasty in osteoarthritis: a 3- to 9-year follow-up study. J Arthroplasty $1995 ; 10: 8-13$.

5. Lindstrand A, Stenström S, Lewold S. Multicenter study of unicompartmental knee revision: PCA, Marmor and St Georg compared in 3777 cases of arthrosis. Acta Orthop Scand 1992;63:256-9.

6. Goodfellow JW, Kershaw CJ, Benson MK D'A, O'Connor JJ. The Oxford knee for unicompartmental osteoarthritis. J Bone Joint Surg [Br] 1988;70-B:692-701.

7. Murray DW, Goodfellow JW, Connor JJ. The Oxford medial unicompartmental arthroplasty: a ten-year survival study. J Bone Joint Surg [Br] 1998;80-B:983-9.

8. Lewold S, Goodman S, Knutson K, Robertsson O, Lidgren L. Oxford meniscal bearing knee versus the Marmor knee in unicompartmental arthroplasty for arthrosis: a Swedish multi-centre survival study. J Arthroplasty 1995;10:722-31.

9. Robertsson O, Knutson K, Lewold S, Lidgren L. Knee arthroplasty for osteoarthrosis and rheumatoid arthritis 1986-1995: validation and outcome in the Swedish National Register. Presented as a scientific exhibit at the annual meeting of the American Association of Orthopaedic Surgeons, Anaheim, 1999.

10. Murray DW, Carr AJ, Bulstrode C. Survival analysis of joint replacements. J Bone Joint Surg [Br] 1993;75-B:697-704.

11. Dorey F, Nasser S, Amstutz $\mathbf{H}$. The need for confidence intervals in the presentation of orthopaedic data. J Bone Joint Surg [Am] 1993;75-A:1844-52.

12. Gutierrez B, Culler SD, Freund DA. Does hospital procedurespecific volume affect treatment costs: a national study of knee replacement surgery. Health Serv Res 1998;33:489-511.

13. Kreder HJ, Williams JI, Jaglal S, et al. Are complication rates for elective primary total hip arthroplasty in Ontario related to surgeon and hospital volumes? A preliminary investigation. Can J Surg 1998;41:431-7.

14. Lavernia CJ, Guzman JF. Relationship of surgical volume to shortterm mortality, morbidity and hospital charges in arthroplasty. $J$ Arthroplasty 1995;10:133-40.

15. Espehaug B, Havelin LI, Engsaeter LB, Vollset SE. The effect of hospital-type and operating volume on the survival of hip replacements: a review of 39505 primary total hip replacements reported to the Norwegian Arthroplasty Register, 1988-1996. Acta Orthop Scand 1999;70:12-8. 